\title{
ESPORTE, INCLUSÃO E EDUCAÇÃO FÍSICA ESCOLAR. EM DEBATE: A ANÁLISE DO PROJETO CID-PARALÍMPICO
}

\section{SPORT, INCLUSION AND SCHOOL PHYSICAL EDUCATION. IN DEBATE: THE ANALYSIS OF THE PROJECT CID-PARALYMPIC}

\author{
André Luís Normanton Beltrame* \\ Marilda Teixeira Mendes ${ }^{* *}$ \\ Maria Márcia Viana Prazeres ${ }^{* * *}$
}

\section{RESUMO}

O objetivo do estudo foi analisar junto a professores de um projeto de atendimento educacional especializado em esporte adaptado, projeto CID-Paralímpico, suas percepções acerca da contribuição do projeto na Educação Física Escolar inclusiva. A pesquisa, por meio de entrevistas com dez professores do projeto, culminou na seleção de duas categorias para análise. Os resultados indicam dificuldades na participação da pessoa com deficiência quando nas aulas de Educação Física Escolar e o reconhecimento difuso do projeto e da função desempenhada por seus professores, que vão a escola orientar e sugerir possibilidades de aulas. O estudo conclui que projeto não se alinha a Educação Física Escolar inclusiva e aponta que a ida de professores do projeto à escola esteja servindo como argumento para aulas individuais à pessoa com deficiência.

Palavras-chave: Atendimento Educacional Especializado; Esporte Adaptado; Inclusão de Pessoas com Deficiências.

\begin{abstract}
The aim of this study was to analyze next to the teachers of a project of educational service specializing in sport adapted, CID-Paralympic project, their perceptions about the contribution of the project in the physical education inclusive classes. The research, by means of interviews with ten teachers project, culminated in the selection of two categories for analysis. The results indicate difficulties in participation of disabled person when in school physical education classes and fuzzy recognition of the project and of the role played by their teachers, who go to school guide and suggest possibilities. The study concludes that project aligns the inclusive school physical education and points out that the departure of teachers to school project is serving as an argument for individual classes to the disabled people.
\end{abstract}

Keywords: Specialized Care; Adapted Sports; Inclusion of people with disabilities.

\footnotetext{
* Mestre e Doutorando em Educação Física pela Universidade Católica de Brasília, bolsista CAPES. Professor de Educação Física da Secretaria de Educação do Distrito Federal - SEDF.

${ }^{*}$ Mestra e Doutoranda em Educação Física pela Universidade Católica de Brasília, bolsista CAPES. Professora de Educação Física na Universidade Federal de Minas Gerais - UFMG.

*** Doutora em Educação Física e Mestra em Gerontologia pela Universidade Católica de Brasília.
} 


\section{INTRODUÇÃO}

Atualmente, a proposta de educação inclusiva no Brasil aponta para a perspectiva de que todas as pessoas independentemente de sua deficiência, origens e talentos frequentem a mesma escola e tenham acesso ao mesmo ensino em sala de aula. Nesse cenário, mesmo reconhecendo controvérsias e contradições ${ }^{1}$, a Educação Especial, através de serviços de suporte à inclusão educacional, passa a exercer um importante papel no sentido de garantir a presença de estudantes ${ }^{2}$ com deficiências no ensino regular.

Ao tratar de propostas para uma educação inclusiva no presente estudo, buscamos refletir acerca de um conceito de inserção na escola regular que ofereça acesso e participação à todas as pessoas, respeitando seus ritmos e peculiaridades (GLAT; PLETSCH, 2012; MANTOAN; PRIETO 2006), conforme preconiza a Política Nacional de Educação Especial na Perspectiva da Educação Inclusiva (PNEE). No documento em tela a educação inclusiva é percebida como um "paradigma educacional (...) que conjuga igualdade e diferença como valores indissociáveis, e que avança em relação à ideia de equidade formal ao contextualizar as circunstâncias históricas da produção de exclusão dentro e fora da escola" (BRASIL, 2008, p.5).

Sob um ponto de vista conceitual a inclusão pode até prescindir de serviços de apoio (MENDES, 2006), todavia esta pesquisa se embasa nas recomendações mais recentes da Resolução CNE/CEB $\mathrm{n}^{\circ} 4 / 2009$ (BRASIL, 2009a) e Parecer CNE/CEB n ${ }^{\circ}$ 13 de 2009 (BRASIL, 2009b), que destacam para a

\footnotetext{
${ }^{1}$ Destaque para três movimentos que representam campos de debate na atual política nacional de inclusão com repercussão no Ensino Especial e Atendimento Educacional Especializado: Plano Nacional de Educação - PNE para o decênio 2011-2020; Manifesto da Comunidade Acadêmica pela Revisão da Política Nacional de Educação Inclusiva e o Manifesto ao Manifesto da Comunidade Acadêmica pela Revisão da Política Nacional de Educação Inclusiva, os dois últimos promovidos por grupos da comunidade acadêmica. ${ }^{2}$ Segundo o artigo $4^{\circ}$ da Resolução n.4 de 02 de outubro de 2009, considera-se público-alvo do Atendimento Educacional Especializado - AEE; I - Alunos com deficiência; aqueles que têm impedimentos de longo prazo de natureza física, intelectual, mental, ou sensorial. II. Alunos com transtornos globais do desenvolvimento: aqueles que apresentam um quadro de alterações do desenvolvimento neuropsicomotor, comprometimento nas relações sociais, na comunicação ou estereotipias motoras. Incluem-se nessa definição, alunos com autismo clássico, síndrome de Asperger, síndrome de Rett, transtorno degenerativo da infância (psicoses) e transtornos invasivos sem outra especificação. III. Alunos com Altas Habilidades/Superdotação: aqueles que apresentam um potencial elevado e grande envolvimento com as áreas do conhecimento humano, isoladas ou combinadas: intelectual, liderança, psicomotora, artes e criatividade.
}

Educação Especial um novo papel na perspectiva da educação inclusiva. Nesse sentido, há a abertura para a existência de atendimento educacional especializado como complementar e auxiliar e não como ação única ou em substituição ao ensino comum da escola regular.

Isto significa dizer que a Educação Especial, historicamente reconhecida por seu caráter assistencialista e beneficente, que tratava de forma isolada a educação da pessoa com deficiência, passa a ter novo direcionamento; deixando de segregar o indivíduo em seu contidiano pedagógico e atuando de forma complementar ao ensino regular, por meio dos serviços de Atendimento Educacional Especializado (AEE). Esses serviços, como por exemplo: o sorobãn, o braile, e no caso do presente estudo, a Educação Física Adaptada (BRASIL, 2004), buscam, por meio de práticas pedagógicas diversificadas eliminar barreiras no processo de ensino e aprendizagem dos alunos com deficiência. Para tanto, procuram por meio de suas ações, práticas pedagógicas que equalizem condições para o acesso e permanência na escola em todas as etapas e modalidades da educação básica (BRASIL, 2009a-b; 2011). Seus objetivos caminham para a garantia da transversalidade das ações do ensino especial no ensino regular, promovendo condições de acesso e participação na escola, e paralelamente, fomentando o desenvolvimento de recursos didáticos e pedagógicos que eliminem barreiras no processo de ensino aprendizagem.

Atendendo a esses pressupostos legais foi criado no Distrito Federal, pela Secretaria de Educação do Distrito Federal (SEDF), o Centro de Iniciação Desportiva Paralímpica (CID-PL). De acordo com sua Orientação Pedagógica (DISTRITO FEDERAL, 2009) o CID-PL é um projeto de AEE que oferece nas escolas, aos alunos com comprometimento funcional físico, auditivo, visual e intelectual, a Educação Física e o desporto adaptado como forma de inclusão. A fundamentação legal do CID-PL está baseada na Lei Orgânica do Distrito Federal de 1993 que em seu Artigo 255 aponta que: "as ações do poder público darão prioridade ao desporto educacional"; Lei de Diretrizes e Bases 9394 (art. 58 e 59) que trata sobre o "atendimento de Educação Especial" e as "garantias aos educandos com Necessidades Educacionais Especiais"; Constituição Federal (art. 206 e 208) que dispõe respectivamente sobre a "igualdade de 
condições para acesso e permanência na escola" e a "garantia do atendimento educacional especializado", dentre outros documentos.

O CID-PL conta para sua realização, com professores de Educação Física do próprio quadro efetivo da SEDF, tendo a tarefa de divulgar o projeto nas escolas públicas da rede, em perímetros que compreendem a região administrativa ou regional de ensino na qual estão lotados. Estes profissionais atuam majoritariamente em escolas públicas e conveniadas da rede pública de ensino e eventualmente em outros espaços públicos de outras Secretarias. Como exemplo: os Centros Olímpicos, administrados pela Secretaria de Esporte, que possuem equipamentos esportivos específicos, como piscina e pista de atletismo. Ao professor também cabe, além das aulas; participar de reuniões semanais, divulgar o trabalho nas escolas convidando estudantes a ingressarem no projeto, entregar relatórios bimestrais das atividades e acompanhar alunos participantes em competições, eventos e festivais. Na sua organização, as aulas do projeto ocorrem às segundas, quartas e sextas, no período matutino e vespertino - em regime de contra-turno escolar - atendendo estudantes da rede pública de ensino, a partir dos 6 anos de idade, que apresentem laudo clínico ou psicopedagógico contendo quadros de deficiência e/ou transtornos (DISTRITO FEDERAL, 2009).

Nesse sentido, a percepção dos professores que atuam no CID-PL do Distrito Federal sobre a relação de seu trabalho com o dos que atuam na Educação Física Escolar foi objeto de investigação.

Em levantamento bibliográfico, realizado em banco de dados de teses e dissertações nacionais, não foram encontrados estudos específicos sobre Educação Física Adaptada e AEE. Entretanto, estudos recentes incluindo artigos, teses e dissertações sobre AEE destacam a importância do tema e a necessidade de sua maior discussão, tanto no que tange a aspectos de formação profissional como a própria compreensão do papel do AEE para o processo de inclusão (DIAS, 2010; QUEIROZ JÚNIOR, 2010; SILVA, 2010; SILVA, 2011; LOPES; MARQUEZINE, 2012; FANTACINI; DIAS, 2015; BELTRAME, SAMPAIO, 2015).

No estudo de Dias (2010), por exemplo, ao debater a prática do AEE para pessoas com deficiência intelectual foi percebido que ainda faltam entendimentos de complementaridade entre o professor de classe comum e o professor de AEE além do reconhecimento de bases conceituais de atendimento para os professores de AEE. Para Lopes e Marquezine (2012), ao analisar a percepção de professores sobre o AEE, revelam que este trabalho não pode ser confundido com reforço escolar ou repetição de conteúdos curriculares da classe regular.

$\mathrm{Na}$ Educação Física Escolar, embora não específico ao AEE, pesquisas sobre a inclusão escolar de pessoas com deficiência têm sido debatidas no meio acadêmico e duas questões particularmente despertam interesse. Primeiramente, por meio da percepção dos professores que reconhecem a legalidade do processo de inclusão, mas encontram-se envoltos em perspectivas de insegurança ou sentimento de incapacidade, o que prejudica a sua implementação de forma satisfatória (ALMEIDA, 2008; GOMES, 2012; GORGATTI, 2009; SANCHES JR. 2009). E, na sequência, relativo as suas próprias práticas pedagógicas, ora otimistas evidenciadas em ações no cotidiano dos alunos (MARTINS, 2014; DUARTE et al. 2015); ou, do contrário, revelando distanciamento em relação às necessidades dos alunos (CHICON et al, 2011; MAHL, 2012).

De maneira geral o que se percebe é que em muitos casos as aulas de Educação Física têm adotado medidas excludentes ao se deparar com as diferenças, ignorando dimensões afetivas, cognitivas e socioculturais no processo de ensino-aprendizagem. $\mathrm{O}$ fato guarda relação histórica a um conjunto de ideias e verdades que determinaram uma prática voltada aos mais habilidosos e vitoriosos, assumindo um caráter unicamente biológico, em detrimento dos que não tem a mesma capacidade (RODRIGUES, 2003; SILVA, SOUSA, VIDAL, 2005; SILVA, SEABRA JR., ARAÚJO, 2008).

Portanto, ao saber que este tipo de serviço, o AEE, nasce oriundo de uma demanda por participação e permanência no sistema de ensino, devendo contribuir para que o aluno com deficiência tenha mais representatividade no cenário escolar, inquiriu-se: como o professor do projeto CID-PL percebe a inclusão ao analisar a relação do projeto com a Educação Física praticada nas escolas. Sendo assim, o objetivo do estudo foi analisar junto aos professores do projeto CIDPL, sua percepção acerca da contribuição do projeto na Educação Física Escolar inclusiva. 


\section{MATERIAIS E MÉTODO}

Optou-se pela pesquisa de abordagem qualitativa, por identificar no estudo a necessidade de compreensão do fenômeno social partindo da descrição de suas experiências (BOGDAN, BIKLEN, 1994). Para a confecção dos dados foi utilizada a entrevista a partir de um roteiro semiestruturado dividido em duas partes. A primeira, abordando questões sobre dados pessoais, profissionais e de ingresso no projeto; e, a seguinte, partindo de uma pergunta geradora sobre inclusão. Assim, na busca por analisar as percepções dos professores que atuam no CID-PL acerca da inclusão das pessoas com deficiência a pergunta geradora foi: "A partir do projeto CID-PL, como você vê a inclusão no âmbito das aulas de Educação Física?”. As entrevistas foram gravadas nos ambientes de trabalho de cada professor, em aparelho MP3/4 (Player Music no Limit) e transcritas para posterior análise.

A análise de conteúdo foi realizada, tendo em vista que este método privilegia as vivências do sujeito, bem como o conjunto de percepções sobre determinado fenômeno (BARDIN, 1992). A técnica de análise de conteúdo escolhida foi a Técnica de Elaboração e Análise de Unidades de Significado desenvolvida por Moreira, Simões e Porto (2005). Essa técnica visa compreender por meio dos discursos, contextos e interpretações que dão significado a um fenômeno.

De acordo com os autores, no nosso cotidiano temos opiniões diferentes acerca dos fenômenos que são externados por meio de juízos de valor. Dentro do conjunto dessas opiniões, que podem ser negativas ou positivas, existem pontos intermediários que "cabe ao pesquisador garimpar e interpretar buscando identificar os significados do fenômeno estudado" (MOREIRA, SIMÕES, PORTO, 2005, p.110).

Para sua realização, a técnica se desenvolve a partir dos seguintes momentos: 1 - Relato ingênuo, que consiste no entendimento do discurso em sua forma original, inclusive relacionando o comportamento do respondente ao sentido da resposta; 2 - Identificação de atitudes, que busca por unidades de significado nos discursos, procurando construir indicadores e categorias que sirvam de referencial para interpretação, e; 3 - Interpretação, que evitando generalizações, procura identificar atitudes e estruturas de pensamento individual que se alinhem a outras respostas.
Após aprovação pelo Comitê de Ética em Pesquisa da Universidade Católica de Brasília - registro: CAAE: 03940412.1.0000.0029 - e a Gerência de Desporto Escolar - GEDESC, órgão responsável pelo projeto CID-PL da SEDF, os professores foram convidados verbalmente em reunião realizada no Centro Interescolar de Educação Física - CIEF. Foram explicados aos presentes os interesses da pesquisa, procedimentos e garantia de anonimato e a confidencialidade dos dados. Aos que concordaram em participar, foram marcados encontros no próprio espaço em que realizavam as aulas do projeto, procedendo a leitura e assinatura do Termo de Consentimento Livre e Esclarecido - TCLE.

\section{RESULTADOS E DISCUSSÃO}

Para a presente pesquisa foram convidados a participar das entrevistas professores do CID-PL de todo o Distrito Federal, envolvendo 8 regiões administrativas e o Plano Piloto. Dos participantes consultados 10 dos 16 convidados aceitaram. Deles, foi observado o seguinte perfil na primeira parte do questionário: Em dados considerados pessoais houve uma maior predominância daqueles que se declaram o sexo masculino $(80 \%)$ com aquelas que se declaram do sexo feminino (20\%) e uma divisão de idades entre aqueles com idades entre 40 à 45 anos e 24 à 35 anos (50\%). Em relação aos dados profissionais, na formação todos tinham Ensino Superior completo na área obtendo a licenciatura plena. Apenas 4 professores tinham especialização, na modalidade lato sensu, relacionada à inclusão ou esporte escolar; e $80 \%$ declararam nunca terem procurado formação continuada para atuação no projeto. Sobre a forma de ingresso 9 participantes foram convidados a ingressar no CID-PL por dirigentes pertencentes ao projeto e outros gestores não ligados diretamente ao projeto, sem a exigência de preparação específica na área da inclusão, bem como, não tiveram qualquer tipo de orientação formalizada.

No conjunto das entrevistas a partir do tema gerador, após a transcrição dos discursos, revelaram-se duas categorias de análise predominantes: 1. A atitude e preparo do professor de Educação Física Escolar para atuar na inclusão; 2 . A contribuição do Atendimento especializado oferecido pelo CIDPL, demonstrando percepções controversas entre o 
papel da professores da escola e do Projeto CID-PL no que concerne ao processo de inclusão, como se observa a seguir.

\section{QUADRO 1: CATEGORIAS DE ANÁLISE}

\begin{tabular}{|c|c|c|c|c|c|c|c|c|c|c|c|}
\hline $\begin{array}{l}\text { Participantes/Categorias } \\
\text { de análise }\end{array}$ & 1 & 2 & 3 & 4 & 5 & 6 & 7 & 8 & 9 & 10 & $\%$ \\
\hline $\begin{array}{l}\text { A atitude e preparo do } \\
\text { professor para atuar na } \\
\text { inclusão }\end{array}$ & $\mathrm{X}$ & $x$ & $\mathrm{x}$ & $\mathrm{x}$ & $\mathrm{x}$ & & $\mathrm{X}$ & $\mathrm{x}$ & & $\mathrm{x}$ & $80 \%$ \\
\hline $\begin{array}{l}\text { A contribuição } \\
\text { do Atendimento } \\
\text { especializado oferecido } \\
\text { pelo CID-PL }\end{array}$ & & $x$ & $\mathrm{x}$ & $\mathrm{x}$ & $\mathrm{x}$ & & & & & & $40 \%$ \\
\hline
\end{tabular}

Fonte: Elaboraração do autor.

A primeira categoria de análise: A atitude e preparo do professor para atuar na inclusão pode ser encontrada nas afirmações de $80 \%$ dos professores do CID-PL (participantes 1,2,3,4,5,7,8,10). Os participantes se referiram a atitudes e preparo dos professores que atuam na Educação Física Escolar, no caso a sua ausência, quando em contato com alunos no seu cotidiano de aulas. Tais narrativas dos entrevistados foram obtidas partindo do observatório que os mesmos possuíam ao realizar visitas nas escolas para divulgação do projeto. No interior das argumentações evidencias apontam que pouca atenção tem sido dada à participação de pessoas com deficiências tendo em vista o que parece ser um despreparo pedagógico e a resistência dos docentes em alterar sua rotina de aula pré-estabelecida.

Eu vejo o professor que segue aquela rotina previamente determinada de muitos anos e o aluno tem que se adequar à aula, senão fica excluído. (Participante 3) Quando vamos às escolas vemos aquele professor que parece não ter qualquer preparo para atender a pessoa com deficiência, deixam a coisa de qualquer jeito. (Participante 7)

A verdade mesmo é que o professor não dá importância ao aluno com deficiência. Falta um comportamento que assuma esses alunos nas aulas. (Participante 8)

O comportamento, a rotina e o preparo dos professores são observados nos discursos. Se percebem afirmações e posturas que não estão abertas às novas possibilidades, necessárias ao movimento de Educação Inclusiva. Há a demonstração de pouco encorajamento por parte dos professores para explorar aulas que conduzam a participação efetiva de todos os estudantes. Essa problemática, que envolvem comportamentos, ações e organização pedagógica do professor, fazem parte do que se tem discutido em estudos recentes (ALMEIDA, 2008; GOMES, 2012; GORGATTI, 2009; SANCHES JR., 2009).

Na pesquisa de Gorgatti (2009), por exemplo, $47,8 \%$ dos 90 professores entrevistados demonstraram não gostar da ideia de ter alunos com deficiência em suas aulas, enquanto $66,6 \%$ relacionavam o pessimismo em trabalhar com os alunos ao seu preparo para ministrar aulas. Com Almeida (2008) há um desdobramento deste cenário, configurado como uma espécie de afastamento do professor em relação ao aluno com deficiência. O autor acrescenta que da constatação unânime de insergurança, entre os professores participantes da pesquisa, está presente sentimento ligado ao medo, receio, ausência de apoio institucional e capacitação teórica para lidar com o diferente.

Em oposição, o estudo de Martins (2014) que conseguiu destacar atitudes classificadas como "positivas" dos professores de Educação Física Escolar, algumas ressalvas são observadas. Assinala, nesse sentido, uma interlocução de tais atitudes a fatores como: idade, nível de ensino, formação específica e experiência em classes inclusivas. No estudo a autora reforça a importância do desenvolvimento por parte dos docentes de uma pedagogia crítica e flexível, agindo colaborativamente com a comunidade educativa. Esta iniciativa, para se tornar possível, parte da assunção de uma cultura inclusiva, espaço em que no centro da comunidade educativa as pessoas e grupos possam externar seus pontos de vista contribuindo para a articulação de metas comuns.

Do que foi tratado até aqui se percebem condutas nas aulas de Educação Física Escolar que caminham em desencontro à perspectivas de diálogo para atender a pessoa com deficiência. Rodrigues (2003) chama atenção nesse ponto ao revelar que a Educação Física como disciplina curricular não pode ser indiferente para com o movimento de Educação Inclusiva. Tal chamamento, mesmo reconhecendo outras dificuldades para a operacionalização das aulas (estrutura, número de alunos, formação dentre outras), traz indicativos pelos quais ações e maneiras diretas do professor acabam sendo uma questão de responsabilidade social e ética (GLAT, NOGUEIRA, 2002). 
Por este ponto de vista a responsabilidade e ética profissional são necessárias para entender que a Educação Física Escolar deve ser capaz de formar um cidadão apto para o "exercício crítico da cidadania e de melhoria de qualidade de vida" (BRASIL, 1997, p.29). Portanto, quem atua na sala de aula tem diante de si compromisso em que não se pode "deixar de pensar em como articular o tempo, o espaço e o conhecimento na Educação Física Escolar que contemple não só o aluno com deficiência, mas o princípio da diversidade da diferença" (SILVA; SOUSA; VIDAL, 2005, p.73).

Ao discorrer sobre o convívio com diferenças e ações que contemplem todos os estudantes, um dos participantes da entrevista sugere uma alternativa para se trabalhar com a pessoa com deficiência:

Tudo tem que ser adaptado ao aluno, igualdade de condições. Se você tem um cadeirante, ele só tem mobilidade com a cadeira, vamos fazer o seguinte: um jogo onde todos tenham o mesmo tipo de mobilidade, claro que não vai dar a cadeira para todo mundo. Todos podem jogar vôlei sentado, por exemplo. (Participante 1)

A iniciativa de incluir o esporte adaptado, como sugere este participante, abre espaço para participação de outras pessoas, com e sem deficiência, nas aulas de Educação Física Escolar. Proceder a esta prática no cenário escolar pode ser uma experiência a mais, contribuindo com a ideia de reconstruir e ressignificar a maneira unilateral pelas quais as práticas esportivas tem sido ensinadas. Neste tocante, a utilização do esporte é observada nos estudos de Chicon et al (2011) e Mahl (2012) com a ressalva de ser um espaço de poucas possibilidades exigindo mudanças no seio de sua estrutura, regras e objetivos para poderem contribuir com a participação dos alunos com deficiência.

Ao assumir o esporte e manipula-lo pedagogicamente, visando a uma apropriação coletiva, se caminha para uma prática inclusiva dentro de um dos conteúdos da Educação Física Escolar. É importante salientar que se trata de buscar um objetivo comum aos estudantes. Neste âmbito não se pode deixar de lado a ideia de que a inclusão se assenta no princípio de um sistema educacional único, que ofereça educação de qualidade para todos. Observa-se que o currículo voltado para as pessoas com deficiência não tem objetivos diferentes dos demais alunos. Possuem, ao contrário, um conjunto de ações que se articulam ao sistema escolar como um todo. Estudos indicam que a partir deste caminho se articulam mudanças mais amplas partindo do projeto politico pedagógico da escola e o sistema escolar não ficando apenas em mudanças pontuais que o professor venha a fazer (GLAT; PLETSCH, 2012; MANTOAN; PRIETO, 2006).

Articular propostas fazendo com que sua penetração no sistema de ensino se constitua como um caminho de aprendizagem para todos é um desafio. Isso porque historicamente os sistemas de ensino tem sido excludentes. O ensino organizado por disciplinas, divisão dos alunos por idade e sobretudo uma prática pedagógica semelhante a todos faz com quem não aprenda com este modelo fique automaticamente excluído. No entanto, no discurso dos participantes pode se perceber uma dificuldade de penetração do projeto do CID-PL na prática dos professores de sala de aula.

\footnotetext{
Muitas vezes tentamos, como parte do nosso trabalho inclusive, falar com os professores que nossos alunos são capazes de muitas coisas, mas vemos que na Educação Física da escola ele (o aluno com deficiência) não faz absolutamente nada. (Participante 5)

Alguns até participam, mas tem que ter perfil, no caso o cadeirante mesmo os colegas estão correndo na quadra e ele fica do lado de fora observando. O professor faz de conta que não está nem vendo. (Participante 7)
}

A identificação desta realidade de ausência de participação de alunos com deficiências nas aulas se configura em algo extremamente preocupante. Não diferente é o "perfil" a que se refere o participante sete. Em ambos os casos parecem não haver estímulos que aproximem o aluno da atividade prática, pois partem de pressupostos que mantém a ênfase do movimento sobre o desempenho e a capacidade.

Chama a atenção a questão do "perfil", em destaque, que trata da condição física do aluno para ingresso na atividade. Significa dizer que caso fosse amputado de braço e a atividade utilizasse só as pernas, por exemplo, seria pré-condição do aluno para participação. Como consequencia, dependeria apenas do interesse do aluno e de seu preparo físico para acompanhar a atividade. De fato, esse modus operandi de ingresso nas aulas nos surpreendeu ao longo das entrevistas. Observamos algo que parece comum aos professores do CID-PL, quando visitam professores em aulas de Educação Física no ensino 
regular, a ausência de qualquer tipo de ação do professor para fazer com que os alunos que possuam uma 'condição física' diferenciada participem das aulas. São dados que trazem fortes evidências da existência de perspectivas tradicionais de ensino nas aulas de Educação Física, conforme reconhecido por Silva, Sousa e Vidal (2005).

Isso nos remonta a perspectiva tradicional da Educação Física Escolar que ao abordar as concepções higienista e militarista assumem opções unicamente práticas em detrimento ao diálogo com perspectivas teóricas que lhe deem suporte. Nesse cenário, onde só quem tem condições físicas realiza as atividades propostas, as pessoas que não têm essa condição, acabam se afastando e legitimando os mais habilidosos (SILVA, SEABRA JR., ARAÚJO, 2008).

A situação pode ser alarmante especialmente se observarmos os dados encontados por Chicon et al. (2011). Em estudo de caso, acompanhando duas crianças, uma com baixa visão e outra com Síndrome de Down, inseridos em turma regular, observaram o que pode estar em curso, uma naturalização da exclusão, pois os alunos não interagiam com outras crianças de forma satisfatória nem na quadra nem no recreio. Os autores indicam que os alunos podem ter assimilado o comportamento ou atitude dos professores uma vez que se observou a perpetuação ou reprodução de atitudes de segregação aos alunos com deficiência. Neste último estudo em especial, os autores observaram que a sala de recurso acabava sendo destino de um dos alunos estudados, em várias ocasiões, em virtude do seu não "enquadramento" nas aulas de Educação Física.

Considerando estas situações fica evidente que ações como a do projeto CID-PL precisa colocar em pauta que a AEE não é ação substitutiva ao ensino regular e que a valorização do professor de AEE e sua experiência pode contribuir para redimensionar tanto a própria aula Educação Física Escolar como a capacitação docente no quesito inclusão. Essa importância respalda-se na reafirmação de que o AEE não é substituição ao espaço de sala de aula comum e sim ação complementar e de ampliação de horizontes (BRASIL, 2009a).

A segunda categoria de análise: A contribuição do Atendimento especializado oferecido pelo CID-PL evidencia-se nas respostas de $40 \%$ dos participantes (Professores 2,3,4,5) por meio de afirmações como a que segue:
Esse trabalho é essencial para inclusão porque se a gente quer incluir a gente tem que dar condições para isso, e no caso isso é o suporte para a sala de aula. (Participante 4)

A resposta do participante acima evidencia o caráter complementar da atividade do projeto que deve contribuir para o processo de inclusão através de metodologias e estratégias que visam a eliminar barreiras a fim de desenvolver a aprendizagem do estudante (BRASIL, 2009a, 2011). Mas, entre os próprios participantes do projeto CID-PL não há muita clareza sobre a relação e possível contribuição deste para a sala de aula do ensino regular, pois no bojo destas ações e ao realizar uma de suas atribuições, nota-se entraves; tanto do contato entre o professor do projeto e o professor da escola como da própria interpretação do professor do projeto ao afirmarem que:

$O$ professor que precisa da gente entra em contato com a nossa coordenação e ela nos pede e ai a gente vai e tenta orientar. Mas a realidade é que ele fica lá sentado. (Participante 5)

No nosso trabalho, por exemplo, é oferecer para ele um trabalho de qualidade para que tenha suporte para a escola regular. Mas em sala de aula esse negócio de inclusão é muito difícil para ele. (Participante 2)

Percebo que muitas vezes o que o professor da escola quer com as nossas visitas é que façamos para ele a atividade. Como uma receita pronta ... então é isso, eu acho que não vamos lá para ensinar e sim para dar aula para o aluno dele. (Participante 4)

Observa-se, em ambos os casos, um descompasso entre o que seria um suporte para o conhecimento do professor de sala de aula e a sua falta de iniciativa para realizá-la. Isso porque o professor que recebe a orientação na escola, aparentemente, não as utiliza com o intuito de que alunos com deficiência participem das aulas de Educação Física Escolar.

$\mathrm{O}$ enfoque dado as interações entre o projeto e a escola nos protifica a dialogar partindo de dois pontos de vista. O primeiro, mais terminativo por assim dizer, fazendo referencia a Glat et al. (2007). O conjunto autoral ressalta que embora a proposta inclusiva empreste nome a muitas experiências escolares o que realmente acontece está ligado ao modelo da integração escolar. Completam dizendo que: 
embora as escolas privilegiem o discurso de aceitação à diversidade, na prática não se modificam para dar conta das especificidades de aprendizagem e desenvolvimento de todos os alunos, deixando aos profissionais e professores de serviços de apoio especializado, a responsabilidade pela resposta educativa a ser dada àqueles que apresentam necessidades educacionais especiais (GLAT, et al., 2007, p.24).

E o segundo ponderando que nesse caso deve haver uma atuação conjunta, uma interface, entre o que o atendimento especializado deve realizar e as aulas da escola, não significando achar que uma tarefa é mais fácil ou detém mais conhecimento que a outra. Ambas devem atuar juntas, "pois um beneficia o desenvolvimento do outro e jamais esse benefício deverá caminhar linear e sequencialmente" (BATISTA, 2009, p.127).

Seguindo por esta linha, Mantoan e Prieto (2006), ao apontar que o compartilhamento de ideias é um dos pontos chaves na formação do professor inclusivo, pontuam que o professor especialista não dividindo suas ações tende a acomodar o professor das classes regulares deixando a falsa impressão que a aprendizagem é do aluno e só o especialista saberá resolvê-lo. Nesse sentido, outros estudos também tratam dessa transferência de responsabilidades e possíveis desdobramentos (DIAS, 2010; QUEIROZ JR., 2010; SILVA, 2011).

Em estudo de Dias (2010) ao abordar metodologicamente a pesquisa-ação, formando grupo de trabalho com profissionais da APAE de São Paulo para debater a prática do AEE, observou algo que vai ao encontro da perspectiva tratada. A autora percebeu uma concepção frequente de que o professor especializado seria o responsável por organizar e realizar as atividades para o aluno com deficiência, como uma substituição ao professor de sala de aula. In loco a pesquisadora percebeu que as professoras de sala de aula tinham dificuldade em interpretar a proposta inclusiva. Inicialmente no trabalho com conteúdos diferenciados e na sequencia a falta de conhecimento mais detalhado, acerca do processo ensino aprendizagem da pessoa com deficiência, que caberia ao professor especializado.

Com Silva (2010) ao analisar os motivos pelos quais professores de sala comum encaminhavam alunos para atendimento especializado chamou a atenção a carência de espaços coletivos de discussão, entre professores (do ensino regular e do AEE). Embora se reconhecessem problemas de estrutura e organização da escola, condições de trabalho, formação continuada e dificuldades para adaptações curriculares dentre outras questões o processo de discussão conjunta entre o professor do AEE e o do ensino regular acontecia de maneira informal e não sistemática. Os encontros informais, segundo a autora, em momentos de intervalo ou na sala dos professores, acabavam sem os devidos registros que documentassem tais conversas abrindo mão "momentos valiosos de interlocução para o professor da classe comum" (SILVA, 2010, p.130).

Em contrapartida, Fantacini e Dias (2015), ao estudar a percepção de professores especialistas sobre as condições de ensino de alunos com deficiência inteletual nas escolas comuns, trazem a percepção de uma das nove professoras entrevistadas destacando a experiência exitosa de ensino colaborativo - parceria entre professores do ensino comum e do AEE para planejamento, instrução e avaliação de um grupo heterogêneo de alunos (MENDES, 2006). Em consonância a esta experiência pode-se entender a observação de um dos participantes da presente pesquisa que aponta para mudanças em sua própria forma de ver a pessoa com deficiência ao declarar:

O CID-PL vem, justamente para isso, mostrar que a pessoa motivada ela tem condições e participa naturalmente. (Participante 3)

Entendendo que historicamente as pessoas com deficiência foram marginalizadas, Silva, Seabra Jr e Araújo (2008) apontam que com a devida adaptação, atendendo ao limite imposto pela deficiência, e uma Educação Física voltada para a participação de todos, naturalmente alunos que antes eram segregados irão conseguir desempenhar com tranquilidade suas atividades nas aulas de Educação Física. Mas é fundamental que a adaptação dos conteúdos atenda cada um, procurando desenvolver suas respectivas potencialidades.

A construção de uma perspectiva de participação da pessoa que não teve acesso não significa uma vantagem e sim uma condição para a participação de todos. Isso é fundamental ao se pensar princípios de uma cultura inclusiva, em que práticas e políticas dialoguem com a celebração das diferenças a fim de que cada indivíduo possa usufruir de seu direito. Para esta finalidade, o diálogo estruturado e sistematizado 
entre professores e professoras que atuam na AEE e na sala de aula regular da Educação Física é fundamental.

\section{CONSIDERAÇÕES FINAIS}

Os resultados revelados por meio das percepções dos professores acerca da contribuição do projeto na inclusão demonstram que o projeto CID-PL não se alinha, em sua plenitude, a Educação Física Escolar inclusiva. Isto ocorre embora se reconheça, em parte, a ideia de inclusão e a ação do projeto neste sentido, com ideias e percepções a respeito. Dados que corroboram com a afirmação são apontados principalmente no momento em que os participantes destacam: dificuldades na participação da pessoa com deficiência nas aulas de Educação Física, diálogo precário dos professores do projeto com os professores de Educação Física Escolar e além disso o reconhecimento difuso do projeto CID-PL e da função desempenhada por seus professores que vão a escola orientar e sugerir possibilidades as aulas.

Sobre as dificuldades na participação da pessoa com deficiência nas aulas de Educação Física Escolar, feitas a partir das observações dos professores do projeto entrevistados, percebem-se atitudes e práticas que afastam o aluno com deficiência das aulas. Práticas que não reconhecem seus praticantes e atitudes que demonstram professores pouco estimulados para promover a participação de seus alunos. Neste cenário pré-estabelecido percebemos que é o desempenho e a capacidade individual que chancelam a aproximação ou não do aluno à atividade.

Outro ponto diz respeito a situações em que o diálogo entre os professores do projeto o os professores da Educação Física Escolar se mostram sem eficácia. Foi identificado que existem sugestões, conforme indicam alguns professores do projeto, mas não há sua efetivação por parte dos professores da escola.

Por último, acerca do reconhecimento do projeto CID-PL por parte dos professores da Educação Física Escolar. Observou-se que o trabalho possui uma direção, no sentido de visitas e orientações, mas o suporte não tem a sequencia devida - a de fazer com que a pessoa com deficiência seja mais participativa nas aulas. Aventamos que o projeto atua de forma a integrar, embora carregue consigo perspectivas de inclusão, e o mais grave: que é o indicativo de que a ida de professores do projeto à escola esteja servindo não para orientar e sugerir possibilidades e sim como argumento para aulas individuais à pessoa com deficiência.

Entre o observado e o idealizado alguns limites do estudo podem ser vistos. Acredita-se que uma maior aproximação ao cenário escolar, por exemplo, entrevistando professores de Educação Física Escolar e alunos, seria uma possibilidade neste sentido, agregaria um outro ponto de vista ao que foi dito. Da mesma maneira, a abordagem as direções escolares procurando reconhecer em que medida o projeto CIDPL é compreendido na escola, seria uma outra possibilidade. Ambas situações se mostram interessantes e necessária na confecção de outros estudos, pois trariam mais nexos e contradições aos fatos apontados pelos professores do projeto CID-PL.

Como perspectivas que se abrem podemos perceber que reconhecer a inclusão não é suficiente, como fazem diretamente ou indiretamente o conjunto dos entrevistados. Uma vez que o cenário ainda aponta para a exclusão das pessoas, que não se adequam às aulas de Educação Física, nos voltamos às necessidades historicamente estabelecidas das pessoas com deficiência. Com vista a um novo cenário que contemple a inclusão, a orientação pedagógica do projeto deve ser revista, partindo de uma organização de suas práticas, tanto para a socialização de seus conteúdos, como para aprimorar e registrar o diálogo com o professor de sala. O projeto deve constituir aí uma ligação com a escola, não só com a ida do professor de AEE para intercâmbios com professores de Educação Física Escolar, mas sua própria inserção no projeto político pedagógico das instituições escolares que estão no seu raio de ação.

\section{REFERÊNCIAS}

ALMEIDA, Marcelo Silveira de. Educação Física Escolar e a inclusão de aluno com deficiência. $102 \mathrm{f}$. Dissertação (Mestrado em Distúrbios do Desenvolvimento) - Universidade Presbiteriana Mackenzie, São Paulo, 2008.

BARDIN, Laurence. Análise de conteúdo. Lisboa: Edições 70, 1992.

BATISTA, Cristina Abranches. Atendimento Educacional Especializado para pessoas com Deficiência Mental. In Mantoan, Maria Teresa Eglér. O desafio das diferenças nas escolas. (2a ed. pp 121-129) Petrópolis,RJ: Vozes, 2009.

BELTRAME, André Luís Normanton; SAMPAIO, Tânia Mara Vieira. Atendimento especializado em esporte 
adaptado: Discutindo a iniciação esportiva sob a ótica da inclusão. Rev. educ. fis. UEM [online]. v.26, n.3, p.377-388. 3.trim. 2015 .

BRASIL. Secretaria de Educação Fundamental. Parâmetros curriculares nacionais: Educação Física/Secretaria de Educação Fundamental.-Brasília: MEC/SEF, 1997.

BRASIL. Constituição Da República Federativa Do Brasil. 1988. Disponível em: <http://www.planalto.gov.br/ ccivil 03/Constituicao/Constitui\%C3\%A7ao.htm>. Acesso em 21 fev. 2015.

BRASIL. Decreto $n^{0} 7611$ - Dispõe sobre a educação especial, o atendimento educacional especializado e dá outras providências, 2011. Disponível em: $<\mathrm{http}: / / \mathrm{www}$. planalto.gov.br/ccivil_03/_Ato20112014/2011/Decreto/ D7611.htm.> Acesso em 21 fev. 2015.

BRASIL. Lei de Diretrizes e Bases da Educação Nacional (LDBEN n9.394/96), 1996. Disponível em:< http://www. planalto.gov.br/ccivil_03/leis/L9394.htm. Acesso em 20/02/2012> acesso em 03 ab.2015.

BRASIL. Política Nacional de Educação Especial na Perspectiva da Educação Inclusiva. Revista Inclusão, Brasília, v. 4, n. 1, p. 7-17, 2008.

BRASIL. Procuradoria Federal dos Direitos do Cidadão. O Acesso de Alunos com Deficiência às Escolas e Classes Comuns da Rede Regular. ( $2^{\mathrm{a}}$ ed.) Ministério Público Federal: Brasília, 2004.

BRASIL. Resolução CEB/CNE $n^{\circ} 4$, de 02 de outubro de 2009. Diretrizes Operacionais para o Atendimento Educacional Especializado na Educação Básica, modalidade Educação Especial. 2009a.

BRASIL. ParecerCEB/CNE n ${ }^{\circ} 13$, de 24 de setembro de 2009. Diretrizes Operacionais para o atendimento educacional especializado na Educação Básica, modalidade Educação Especial. 2009b.

CHICON, José Francisco; MENDES, Katiuscia Aparecida; DE SÁ, Maria das Graças. Educação física e inclusão: a experiência na escola azul. Movimento, Porto Alegre, v. 17, n. 4, p. 185-202, out./dez. 2011.

DIAS, Marília Costa. Atendimento educacional especializado complementar e a deficiência intelectual: considerações sobre a efetivação do direito à educação.156 f. Dissertação (Mestrado) - Programa de Pós-graduação em Educação, USP, São Paulo. 2010.

DISTRITO FEDERAL. Orientação pedagógica do Centro de Iniciação Paralímpica - CID-PL. Secretaria de Estado de Educação do Distrito Federal, 2009.

DUARTE, Anne Caroline; BORELLA, Douglas Roberto; HARNISCH, Gabriela Simone; FRANK, Robson; SCHONE, Angela. Professores de Educação Física e suas práticas pedagógicas em classes que alunos com deficiência estão inseridos. Pensar a Prática, Goiânia, v. 18, n. 1, jan./ mar. 2015.

FANTACINI, Renata Andrea Fernandes; DIAS, Tárcia Regina da Silveira. Professores do Antendimento Educacional Especializado e a Organização do ensino para o Aluno com Deficiência Intelectual. Revista Brasileira de Educação Especial, Marília, v. 21, n. 1, p. 57-74, jan/mar. 2015.

GLAT, Rosana et al. Estratégias pedagógicas para a inclusão de aunos com deficiência mental no ensino regular. In: GLAT, Rosana (Org.). Educação inclusiva: cultura e cotidiano escolar. Rio de Janeiro: 7 Letras, 2007.

GLAT, Rosana; PLETSCH, Márcia. Inclusão escolar de alunos com necessidades especiais. Rio de Janeiro: EdUERJ, 2012.

GLAT, Rosana; NOGUEIRA, Mário Lúcio de Lima. Políticas educacionais e a formação de professores para a educação inclusiva no Brasil. Revista Integração, Brasília, v.14, n. 24, p. 22-27. 2002.

GOMES, Ana Elizabeth Gondim. Inclusão de alunos com deficiência nas aulas de Educação Física Escolar em escolas públicas municipais de Fortaleza (CE). 158 f. Tese (Doutorado em Distúrbio do Desenvolvimento) Universidade Presbiteriana Mackenzie, 2012.

GORGATTI, Márcia Greguol; DE ROSE JÚNIOR, Dante. Percepções dos professores quanto à inclusão de alunos com deficiência em aulas de educação física. Movimento, Porto Alegre, v. 15, n. 2, p. 119-140, abr./jun. 2009.

LOPES, Esther; MARQUEZINE, Maria Cristina (2012). Sala de Recursos no Processo de Inclusão do aluno com Deficiência Intelectual na Perepção dos Professores. Revista Brasileira de Educação Especial, Marília, v. 18, n. 3, p. 487-506, jul./set. 2012.

MAHL, Eliane. Práticas pedagógicas dos professores de Educação Física frente a inclusão de alunos com deficiência. 153 f. Dissertação (Mestrado) - Programa de Pós-graduação em Educação Especial, UFSCAR, São Carlos, 2012.

MANTOAN, Maria Teresa Eglér; PRIETO, Rosângela Gavioli. Inclusão escolar: pontos e contrapontos. São Paulo: Summus, 2006.

MARTINS, Celina Luísa Raimundo. Educação Física Inclusiva: Atitudes dos Docentes. Movimento, Porto Alegre, v. 20, n. 2, p. 637-657, abr./jun. 2014.

MENDES, Enicéia Gonçalves. A radicalização do debate sobre inclusão escolar no Brasil. Revista Brasileira de Educação, v.11, n. 33, p. 387-405, set./dez. 2006.

MOREIRA, Wagner Wey; SIMÕES, Regina; PORTO, Eline. Análise de conteúdo: técnica de elaboração e análise 
de unidades de significado. Revista Brasileira de Ciência e Movimento, v.13, n.4, p. 107-114. 2005.

QUEIROZ JUNIOR, Edson. Formação continuada de professores para 0 atendimento educacional especializado: desafios e perspectivas. $117 \mathrm{f}$. Dissertação (Mestrado) - Programa de Pós-graduação em Educação, USP, São Paulo. 2010.

RODRIGUES, David António. Educação Física perante a educação inclusiva: reflexões conceptuais e metodológicas. Revista da Educação Física/UEM. Maringá, v.14, n.1, p. 67-74. 2003.

SANCHES JÚNIOR, Moisés Lopes. Uma leitura da questão da deficiência e da inclusão no ensino municipal de Hortolândia: olhares e ações da docência de educação física e seus pares. 2009. 85 f. Dissertação (Mestrado) Programa de Pós-graduação em Educação Física, UNICAMP, Campinas, 2009.

SILVA, Rita de Fátima; SEABRA JR. Luiz; ARAÚJO, Paulo Ferreira de. Educação Física Adaptada no Brasil: da história à inclusão educacional. São Paulo: Phorte, 2008.

SILVA, Fabrícia Gomes da. Inclusão escolar de alunso com deficiência intellectual: 0 atendimento intellectual especializado (AEE) em discussão. 166 f. Dissertação (Mestrado) -Centro de Educação, UEC, Fortaleza. 2011.

SILVA, Maria de Fátima Neves da. Encaminhamento de alunos para sala de recursos: análise sobre os argumentos apresentados pelos professores de classes comuns. $139 \mathrm{f}$. Dissertação (Mestrado) - Programa de Pós-graduação em Educação, USP, São Paulo. 2010.

SILVA, Régis Henrique dos Reis; SOUSA, Sônia Bertoni; VIDAL, Maria Helena Candelori. Educação física escolar e inclusão: limites e possibilidades de uma prática concreta. In: anais do iv simpósio de estratégias de ensino em educação/ educação física escolar. v.2, p.66-76. Revista Especial de Educação Física, 2005.

Recebido em: 14.06.2017

Aceito em: 24.08.2017 